\title{
Design and Performance Evaluation of an Indirect Solar Dryer
}

\author{
Bashir Aliyu*1, Bwade EK ${ }^{2}$ \\ ${ }^{1}$ Department of Agricultural \& Environmental Engineering, Modibbo Adama University of Technology, Yola, Adamawa, \\ Nigeria \\ ${ }^{2}$ Department of Agricultural \& Bio-Environmental Engineering Technology, Federal Polytechnic, Mubi, Adamawa, Nigeria
}

\begin{abstract}
An attempt to minimize post harvest losses of tomato that gluts in Mubi, Adamawa State, Nigeria in the months of August to October annually, an indirect solar dryer was designed, fabricated and evaluated based on meteorological data of mean monthly values of ambient temperature, wind speed, and global solar radiation, which were $22.2^{\circ} \mathrm{C}, 3.64 \mathrm{~m} / \mathrm{s}$, and $206 \mathrm{~W} / \mathrm{m}^{2}$ respectively. The designed dryer has a solar collector tilted at an angle of $20.26^{\circ} \mathrm{C}$ to the horizontal with the air mass-flow rate and overall mean drying rate of $3.106 \times 10^{-3} \mathrm{~kg} / \mathrm{s}$ and $0.140 \mathrm{~kg} / \mathrm{h}$. It also had a lagging material of thickness $0.065 \mathrm{~m}$ and an air volumetric flow rate of $0.115 \mathrm{~m}^{3} / \mathrm{s}$. Evaluation of the dryer revealed that within the studied months, the dryer requires $50.8 \mathrm{~h}$ to dry tomato from a postharvest moisture content of $95.6 \%$ (d.b) to a storage moisture content of $15.8 \%$ (d.b). In the light of the tomato-fruit dryers developed and evaluated in other regions of the world, further researches need to investigate the effects of incorporating either an additional source of heat or a heat reservoir to ensure day and night time drying, which will further enhance the drying rate and consequently minimize drying duration.
\end{abstract}

Keywords: Solar Dryer, Radiation, Tomato, Moisture Content, Sun Drying, Postharvest.

\section{Introduction}

Tomato- Solanum Lycopersicum is the edible, red, berry plant. It originated in western South America \& Central America. Its domestication and usage as a cultivated food may have originated with the indigenous peoples of Mexico.

Tomatoes are the significant or main source of flavor known as umami. The tomato is consumed in different ways, raw or cooked, in dishes, as a sauce, in salads and drinks. While tomatoes are fruits and botanically termed as berries they are commonly used as a vegetable or side dish. there are Numerous varieties of the tomato plant that are grown widely in temperate climates across the world, with greenhouses allowing for the production of tomatoes in all seasons throughout the year. Tomato plants typically grow to the height of 1 meters - 3 meters $(3-10 \mathrm{ft})$. They are vines that have a weak stem which sprawls \& typically needs support while growing. Indeterminate tomato plants are perennials in native habitat, but are also cultivated as annuals. Determinate or bush, plants are annuals and stop growing at a certain height $\&$ produce a crop all at once. The size of the tomato differs according to the cultivar, with the range of 1 $\mathrm{cm}-10 \mathrm{~cm}(1 / 2-4 \mathrm{in})$ in width. Tomatoes are as warm-season annuals that grows best when the soil temperature is at least $55^{\circ} \mathrm{F}$ $\left(12^{\circ} \mathrm{C}\right) \&$ the air temperature ranges from $65^{\circ} \mathrm{F}$ to $90^{\circ} \mathrm{F}\left(18^{\circ} \mathrm{C}\right.$ $32^{\circ} \mathrm{C}$ ). Tomatoes are commonly grown from seedlings and are later transplanted into the garden. The poor taste and lack of sugar in modern gardening \& commercial tomato varieties resulted from breeding the tomatoes to ripen uniformly red. This change occurred after the discovery of a mutant " $u$ " phenotype in the middle of the 20th century that ripened "uniformly". This was widely cross-bred to produce a red fruit without any typical green ring around the stem on uncross-bred varieties. Prior to general introduction of this trait, most of the tomatoes are produced which have more sugar during ripening, and are sweeter and more flavorful.

Tomatoes are often grown in greenhouses in cooler climatic conditions \& cultivars such as the British 'Moneymaker' and a number of cultivars grown in Siberia are specifically meant for indoor growing in nurseries.

Tomato production in greenhouse is large-acreage commercial and owner-operator stand-alone or multiple-bay greenhouses are rapidly increasing which is the main reason for availability of fruit during all the times of the year when field-grown fruit is not readily available in the market. Smaller sized fruit (cherry and grape), or cluster tomatoes (fruit-on-the-vine) are the fruit of choice ideal for the large commercial greenhouse cultivation while the varieties of beefsteak are the good choice for owneroperator growers.

While coming to harvesting, to facilitate transportation \& storage tomatoes are often picked unripe when they are still in green colour and ripened in storage with ethylene (ripening agent).

A machine-harvestable variety of tomato in combination with the development of a suitable harvester, revolutionized the tomatogrowing industries. These types of tomatoes are grown commercially near plants that process tomatoes, tomato sauce, and tomato paste. They are harvested when they are ripe with red colour \& are flavorful when picked during harvesting. California is a major center of this kind of commercial tomato production and it produces about a third of the processed tomatoes produced worldwide.

Tomatoes can be kept best at room temperature when they are unwashed and out of direct sunlight. It is not recommended to refrigerate them as it can harm/affect their, the flavor or reduces their flavor. Tomatoes are stored at cold tend to lose their flavor

Volume 4, Issue 4 
permanently. Unripe tomatoes can be kept in a paper bag till ripe. It is easy to preserve them whole in pieces, as a tomato sauce or paste by home canning methods. Tomatoes are acidic enough to process them in a water bath rather than a pressure cooker as like most of the vegetables require. The fruit can also be preserved by drying, often in the sun \& sold either in jars or in bags with oil.

Some common tomato pests are cutworms, stink bugs, tomato hornworms, tobacco hornworms, tomato fruit worms, aphids, cabbage loopers, whiteflies, flea beetles, red spider mite, slugs \& Colorado potato beetles etc. The tomato russet mite and Aculops
Lycopersici feeds on foliage \& young fruit of tomato plants, causing shriveling, necrosis of leaves, flowers, and fruit, possibly killing the plants Postharvest handling practices like harvesting, cleaning or disinfecting, pre-cooling, sorting, grading, packaging, storage \& transporting played an important role in maintaining quality \& extending shelf life of the tomato fruits after their harvest. Tomato quality components include appearance (color, size, shape, freedom from defects and decay), firmness, flavor, and nutritional value. Color of the fruit, its firmness, flavor, nutritive value \& safety of tomatoes are related to their composition at the time of harvest and compositional changes during the postharvest handling.

\section{*Correspondence To:}

Department of Agricultural \& Environmental Engineering

Modibbo Adama University of Technology

Yola, Adamawa

Nigeria

Tel: +2347069070152

E-Mail: bashirfuty@yahoo.co.uk 